\title{
Permanecer ou desistir? Mulheres na graduação em engenharia e tecnologias na UTFPR/Guarapuava, Brasil
}

To stay or to give up: women in undergraduate programs in engineering and technology at UTFPR, Guarapuava, Brazil

Luciana Rosar Fornazari Klanovicz ${ }^{1}$

Valéria Aparecida Monteiro de Oliveira ${ }^{2}$

Resumo: Neste artigo analisamos motivações e problemas institucionais que fazem com que mulheres em cursos de Engenharia e Tecnologias desistam ou permaneçam na graduação. Investigamos relatos de estudantes que vivenciaram a graduação entre 2012 e 2019 na Universidade Tecnológica Federal do Paraná, campus Guarapuava, Brasil. Esse locus é entendido como microcosmo de divisões de gênero na formação acadêmica que são mais amplos e que revelam assimetrias de acesso e de permanência de mulheres no sistema universitário brasileiro. Para isso, trabalhamos com uma abordagem que aproxima Estudos de Gênero e Ciências, pensando relações entre homens e mulheres no âmbito das relações de poder e usos sociais de instituições acadêmicas. Como resultado, acompanhamos dados de matrículas, permanências e desistências por gênero na instituição. $O$ estudo aponta para a necessidade de ações instituições de combate à discriminação de gênero, e ao desenvolvimento e estratégias de permanência de estudantes mulheres nos cursos de graduação.

Palavras-chave: Gênero. Ciência. Ensino superior. 
Abstract: In this article we analyze motivation and institutional problems that force women engaged in Engineering and Technology undergraduate programs to drop out or to stay in the univeristy. We interviewedd undergraduate female students enrolled in Engineering programs at Universidade Tecnológica Federal do Paraná - UTFPR, campus Guarapuava, Brazil, between 2012 and 2019. UTFPR is a locus for gender divisions in academic education that reflect broader access and permanence gender asymmetries in Brazilian university system. To read this phenomenon, we adopted a Gender and Science approach, unerstanding relationships between men and women within power relations and social uses of academic institutions. As a result, we tracked enrollment, stay and dropout data by gender at the institution. The study points to the need for institutional actions to combat gender discrimination, and to develop strategies for female students permanence in undergraduate Engineering and Technology programs.

Keywords: Gender. Sciences. Higher education.

${ }^{1}$ Universidade Estadual do Centro Oeste do Paraná | Programa de Pós-Graduação Interdisciplinar em Desenvolvimento Comunitário | Departamento de História | Guarapuava | PR | Brasil. Contato: lucianarfk@gmail.com. ORCID: http://orcid.org/0000-0001-6956-1306

${ }^{2}$ Universidade Tecnológica Federal do Paraná | Núcleo de Atendimento às Pessoas com Necessidades Específicas | Departamento de Educação | Guarapuava | PR | Brasil. Contato: valeriamonteiro@utfpr.edu.br. ORCID: http://orcid.org/0000-0002-0592-4590

- Recebido em: 22 de novembro de 2019

- Aprovado em: 20 de outubro de 2020

DOI: http://dx.doi.org/10.1590/S1414-40772021000100008

Este é um artigo publicado em acesso aberto sob uma licença Creative Commons https://creativecommons.org/licenses/by-nc/4.0/ 


\section{Introdução}

No Brasil o acesso ao ensino superior tem uma história de discriminação e elitização, mesmo sendo direito assegurado pela Constituição de 1988 e reafirmado pela Lei de Diretrizes e Bases da Educação Nacional - Lei 9.394/96 (BRASIL, 1996) (GISI; PEGORINI, 2016). O caso da discrepância entre matrículas de homens e mulheres em cursos de Engenharia e de Tecnologia no Brasil e em diversos países é ainda um sintoma de um tipo de discriminação, o de gênero (CASAGRANDE, 2018, p. 75). Atualmente, menos de 40\% das matrículas nesses cursos em todas as instituições do país estão ocupadas por mulheres. Pensar engenharias e cursos de dimensão tecnológica significa percorrer uma história que constituiu espaços masculinos de conhecimento, carregados de atributos como força, razão, competitividade, capacidade de abstração, objetividade, frieza, austeridade, ou seja, os lugares do masculino (BITENCOURT, 2010).

Durante a vida de ingressantes no ensino superior - a depender da geração, de condições emocionais, socioeconômicas, da raça e do gênero - condições materiais e não materiais de existência exercem muita pressão e as escolhas acabam por expressar subjetividades produzidas no âmbito de um processo descentrado de funcionamento do que Guattari e Rolnik (2005) chamou de máquinas de expressão moldadas por sistemas extrapessoais, extragrupais e infraestruturais, mas que não deixam de considerar a própria individualidade.

Entre os processos de subjetivação descentradamente constituídos, consideramos, para a construção deste artigo, as vivências de universitárias em cursos de Engenharia e de Tecnologia com relação às identidades de gênero percebidas intersubjetivamente. Nosso interesse é perceber, na história de cursos superiores majoritariamente ocupados por homens, quais são os anseios e as atitudes de mulheres que habitam esses campos de conhecimento. Nesse sentido, busca-se compreender a trajetória subjetiva de permanência/desistência de mulheres em cursos de graduação em áreas das Engenharias e Tecnologias com base em relatos oriundos das vivências de estudantes da Universidade Tecnológica Federal (UTFPR), campus Guarapuava, no Paraná. Este espaço institucionalizado de ensino superior de engenharias e tecnologias atinge a trajetória subjetiva de mulheres, em alguns casos, interseccionalmente, envolvendo uma dupla vertente opressiva que aproxima gênero e raça, que acaba por constituir múltiplas identidades oprimidas a partir do estabelecimento simultâneo de, no mínimo, dois sistemas de opressão, o de raça e o de gênero (mas que pode ser também transpassado por classe, geração, região, entre outros). A interseccionalidade desses sistemas permite perceber nos relatos apresentados que não é possível reduzir desistência ou permanência a apenas um 
desses sistemas, o que fica evidente em culturas institucionais, comportamentos cotidianos, normas e escolhas do cotidiano. Conforme pontou Kimberlé Crenshaw et al. (2019), ainda em um momento em que a interseccionalidade estava sendo construída conceitualmente, é preciso 'desmarginalizar' opressões nas dimensões estrutural, política e representacional. Ao considerar tal perspectiva, as estudantes que relatam suas experiências de permanência/desistência no/do ensino superior em Engenharias e Tecnologias, permitem, no âmbito da investigação, o desvelamento de dimensões de poder constituídas e mantidas por meio de vários aspectos da identidade (COLLINS, 2000). Ao contrário de abordagens unitárias ou aditivas de teorizar a opressão, que privilegiam uma categoria fundacional e apenas "adicionam" outras a ela, a interseccionalidade argumenta que só categorias de análise múltiplas e co-constituintes é que podem operar e salientar de maneira equitativa a construção de práticas institucionalizadas e experiências vividas (COLLINS, 2000).

Para discutirmos o tema, utilizamos relatos (R...) produzidos por ex-graduandas de cursos de Engenharia e de Tecnologia da UTFPR-Guarapuava, que é uma instituição de ensino superior nova no âmbito das universidades federais, constituída em meio ao processo igualmente recente de expansão de instituições federais de ensino superior dos últimos governos populares. Desde 2003, o governo federal passou a redimensionar paulatinamente a estrutura de ensino superior pública federal, que veio a desembocar no Programa de Reestruturação e Expansão das Universidades Federais (REUNI) (BRASIL, 2007).

Antes do REUNI, uma operação nacional começou a organizar a transformação de centros federais de educação tecnológica nas novas Universidades Tecnológicas Federais. O Paraná criou a UTFPR nesse processo, por meio da Lei 11.184, de 7 de outubro de 2005 (BRASIL, 2005). O campus Guarapuava começou suas atividades em 2011, com o Bacharelado em Engenharia Mecânica e o Curso Superior de Tecnologia de Sistemas para a Internet. No momento da escrita deste artigo, de 976 estudantes de graduação do campus, apenas 184 são mulheres (não atingindo $20 \%$ do corpo discente). No quadro multicampi da UTFPR, de 26.726 matrículas, 8.749 são de mulheres (pouco mais de 30\%). A realidade assimétrica de gênero da UTFPR só é invertida em favor das mulheres nos cursos de Engenharia de Bioprocessos e Licenciatura em Ciências Biológicas.

Os relatos foram transcriados considerando a confidencialidade e sigilo, com atribuição de pseudônimos e compreendem experiências vivenciadas em uma universidade que vem sendo construída em termos infraestruturais, institucionais e acadêmico-científicos ao mesmo tempo em que as vidas privadas de seus corpos docente e discente. Não é forçoso observar, nesse sentido, que às experiências de migração, de ansiedade por espaços novos que serão bastantes 
presentes nos relatos aqui trabalhados relacionam-se de maneira íntima com uma universidade que foi acomodada provisoriamente em prédios de outra instituição pública de ensino superior no município de Guarapuava, que é a Universidade Estadual do Centro-Oeste (Unicentro), no campus Santa Cruz, marcadamente habitado por cursos de Ciências Humanas, Letras e Artes. A UTFPR-Guarapuava, voltada às Engenharias e às Tecnologias, passou a ter sede própria a partir de 2014 e esse curto período "nômade" também é tomado como fundamental para a vida de suas primeiras estudantes.

Entendemos, assim, que os relatos são documentos provocados (PORTELLI, 1997) para compreender como se articulam as experiências de permanecer ou desistir em cursos de engenharia ou tecnologia a partir de relatos de mulheres jovens em formação profissional considerando a dimensão assimétrica de gênero nesses cursos tradicionalmente tidos como "masculinos". Ademais, tomamos esses relatos como trajetórias subjetivas que se apoiam antes nos processos identitários individuais no sentido em que seu ponto de partida está no relato do próprio percurso por indivíduos (DUBAR, 1998, p. 21). A principal ideia deste tipo de pesquisa é que colocando o percurso em palavras, em que o foco é o sujeito, se organiza o discurso, a partir de categorias de análises e confere-lhe um significado social.

\section{Gênero, engenharias e tecnologias}

Ao longo do percurso formativo das ciências modernas, os primados da razão e da objetividade do trabalho científico excluíram, pelo menos até grande parte do século $\mathrm{XX}$ as mulheres do próprio cenário constitutivo. Essa história produziu a percepção de que a ciência tem gênero e é masculina (SCHIEBINGER, 2001; CHASSOT, 2003).

Cecília Sardenberg (2007, p. 95) observa, ademais, que a ciência se estabelece por meio de "uma lógica binária a partir de pares de opostos: sujeito/objeto, mente/corpo, razão/emoção, objetividade/subjetividade, transcendente/imanente, cultura/natureza, ativo/passivo, etc.”. Essas distinções características das ciências vieram a construir espaços privilegiados de acesso, no que diz respeito às carreiras de cientista, e assimetria de gênero passou a ser elemento constitutivo de algumas áreas científicas, observando-se dicotomias e divisões categóricas entre homens e mulheres com relação a campos de conhecimento (SCHIEBINGER, 2001, p. 40-1).

Os estudos de gênero passaram a pontuar esses desenvolvimentos históricos, criticando essencialismos e a defesa de uma separação biológica entre homens e mulheres no que diz respeito às questões intelectuais, emocionais e comportamentais. Londa Schiebinger (2001) observa que tais concepções definem uma diferença nas habilidades intelectuais para homens e 
para mulheres, e usa a expressão ciências duras e ciências moles para explicar como essa relação ocorre. Para a autora a "dureza é pensada para definir uma hierarquia das ciências. [...] é determinada pelo grau no qual a ciência é tida como erigida sobre leis fundamentais que descrevem a realidade" (p. 297).

$\mathrm{Na}$ esfera social do mundo científico, nesse sentido, Pierre Bourdieu e Jean-Claude Passeron (1998) enfatizaram que interesses de pesquisa são permeados e condicionados pela realidade social. Há, dessa forma, determinações expressas por quem financia a pesquisa, por quem a avalia, por quem a constrói e para quem são destinados privilégios em cada campo de conhecimento. No mundo contemporâneo, campos que vieram a ter proeminência devido aos usos sociais da ciência são engenharias, medicina ou ainda direito; todas áreas de formação nas quais mulheres adentraram em época muito mais recente, ainda na metade do século $\mathrm{XX}$, trazendo conflitos, tensões e novas experiências nos diversos loci do fazer científico, especialmente aqueles tidos como masculinos hegemonicamente.

A construção da imagem de masculino vinculada a Engenharia pode ser pensada no sentido que Bourdieu (2004) atribuiu ao uso social da ciência. Como profissão não tinha o mesmo prestígio que veio a encontrar entre os séculos XIX e XX. Eurocêntrica e fomentada especialmente no âmbito de projetos colonialistas, ela passou a adquirir importância, principalmente em virtude da ampliação dos conhecimentos práticos a serviço de estados, da industrialização e do capital. Seu ensino acabou sendo destinado a homens seguindo imperativos advindos do mundo militar, da tecnologia, mas também do ainda forte sentido pragmático e masculinizado dado à objetividade do conhecimento. Nas escolas politécnicas que passaram a fornecer engenharias como formação no Brasil do final do século XIX, a formação refletia concepções militares de educação, a participação apenas de homens na formação educacional, o processo rigoroso e disciplinar direcionado a ideia de educar pela ordem, a exigência de força física e destreza, e o foco nas disciplinas ligadas à matemática e a física. A relação entre homens e Engenharia fez com que "os indivíduos pertencentes a esse grupo social tendessem e 'precisassem' incorporar determinados aspectos culturais para serem reconhecidos e se reconhecerem como tais" (BITENCOURT, 2010, p. 174). Assim, entre os aspectos significativos envolvidos no processo, estavam a capacidade de transmitir a informação de que a engenharia é uma profissão de homens (LOMBARDI, 2004).

As configurações de constituição do espaço institucional de formação da Engenharia auxiliam na compreensão das dificuldades para que as mulheres acessassem essa área. Mudanças ocorridas na sociedade brasileira nos aspectos econômicos, as lutas feministas e os 
movimentos sociais, contudo, favoreceram a entrada das mulheres nas Engenharias, construindo novas alteridades e espaços de mudança nesses ambientes (BITENCOURT, 2010).

Segundo Lombardi (2004) as primeiras áreas na Engenharia em que as mulheres apresentam formação no Brasil foram Engenharia Química (1928), Engenharia Civil (1947), Engenharia Elétrica (1958) e Engenharia de Minas (1974). A autora destaca a dificuldade de acompanhar a evolução da presença das mulheres em cursos de Engenharias no país, por conta da ausência de registro por sexo nas instituições de ensino universitário até um dado momento.

Luciana R. F. Klanovicz (2011), mostra que houve aumento total de matrículas de mulheres em cursos de engenharia de duas instituições públicas do sul do Brasil, a Universidade Estadual de Maringá (UEM) e Universidade Federal de Santa Catarina (UFSC), entre os anos de 1998 a 2009. A autora observa que há diferença na participação das mulheres entre os cursos, pontuando, contudo, que há em algumas áreas da Engenharia maior equilíbrio e constância na participação das mulheres como é o caso da Civil e da Química, que na UFSC.

As informações produzidas pelo trabalho de Klanovicz (2011) e Lombardi (2004) evidenciam que há nas Engenharias, concentrações masculinas na ocupação de vagas nas universidades, e posteriormente na colocação no mercado de trabalho. As autoras estudadas salientam que as dificuldades de ocupação das mulheres nas áreas das Engenharias, assim como, nas tecnologias, estão associados a fatores relacionados: a falta de estímulos às meninas nos ambientes escolares para o desenvolvimento de atributos que representam a carreira nestes espaços como: "agressividade, abstração, competitividade, entre outros considerados masculinos" (BITENCOURT, 2010, p. 177); ao preconceito existente relacionado as carreiras que exige conhecimento de lógica e razão, condição atribuída aos homens; a falta de investimento público para uma política de bolsas de estudos para estimular mulheres a adentrar estes espaços acadêmicos; o fator cultural que constrói nas mulheres o desejo de buscar as profissões tidas como femininas (TABAK, 2002); e a dificuldade de se colocar profissionalmente nesta áreas (LOMBARDI, 2004).

Kariane Svarcz (2017) mostra, nesse sentido, que o Brasil tinha, em 2013, 109.799 doutores sendo que mulheres representavam 46,78\% de total de títulos. A distribuição por sexo e a relação com as áreas de atuação mostrava que as mulheres ocupavam majoritariamente as áreas de humanas e os homens as ciências exatas. A autora constatou que nessa época o número de doutores na área da Engenharia era de 10.301 (sendo 2.515 mulheres) eram mulheres. Esses dados se repetem no processo de formação profissional, e as raízes desta questão estão fincadas na história da produção da ciência e na constituição das áreas de formação em Engenharia e Tecnologias, que se constituíram por homens e para atender interesses de homens. Nesse 
sentindo, nos indagamos: como gênero está relacionado com a permanência e a desistência de mulheres nestas áreas?

Josemeire Sobreira (2006) pontuou a existência de guetos masculinos no âmbito da UTFPR, apesar de crescente participação de mulheres em alguns cursos. A autora analisa que há predominância de padrões masculinizados de gênero e que o mercado de trabalho não está totalmente receptivo às engenheiras. Em certa medida isso se deve à constituição histórica dos campos tecnológicos e das engenharias no país. No caso da UTFPR, que tem 13 campi (Apucarana, Campo Mourão, Cornélio Procópio, Curitiba, Dois Vizinhos, Francisco Beltrão, Guarapuava, Londrina, Medianeira, Pato Branco, Ponta Grossa, Santa Helena e Toledo), é interessante observar que em nenhum deles as mulheres matriculadas chegam a 50\% do corpo discente, e que as menores proporções estão em Guarapuava (18,85\%) e Cornélio Procópio $(16,91 \%)$.

Guarapuava conta com cursos de Engenharia e Tecnologia enquanto que Cornélio Procópio oferta Bacharelado em Engenharia de Software, Engenharia da Computação, Engenharia de Controle e Automação, Engenharia Elétrica, Engenharia Eletrônica, Engenharia Mecânica, Licenciatura em Matemática e Tecnologia em Análise e Desenvolvimento de Sistemas. Os campi com menor disparidade entre homens e mulheres matriculados são Santa Helena e Dois Vizinhos, que oferecem Licenciatura em Ciências Biológicas, respectivamente com $77 \%$ e $73 \%$ das vagas ocupadas com mulheres. Em Dois Vizinhos há outros dois cursos com maior proporção de mulheres: Zootecnia com $61 \%$ e Engenharia de Bioprocessos e Biotecnologia com 64\%.

Os dados sugerem que gênero influencia escolhas acadêmicas ou uma divisão sexual nas áreas do conhecimento. Entre os campi, aqueles que ofertam grande parte de seus cursos nas áreas das Engenharias e/ou Tecnologias observa-se a predominância masculina em matrículas. As mulheres acabam habitando mais o campo das licenciaturas ou de engenharias novas como a de Bioprocessos.

No campus Guarapuava, a relação entre matrículas de estudantes locais e migrantes é outro ponto que se junta à questão de gênero já citada. A proporção entre estudantes regulares segundo procedência familiar evidencia que cursos superiores tecnológicos são mais habitados por estudantes locais e que bacharelados têm sido ocupados por estudantes de fora do município. Em todos os cursos, mulheres ocupam menos de 50\% das vagas.

Ao ingressar na universidade, os/as estudantes se mostram preocupados/as com as mudanças relacionadas à rotina de estudos, que em muito se diferencia das vivências escolares. Em alguns casos, trata-se de um período conturbado pois exige "desde o domínio da linguagem, 
de métodos de estudo/aprendizagem, dos espaços acadêmicos, até a assimilação dos valores e procedimentos da nova instituição" (ANDRADE, 2014, p. 10). Além da autonomia acadêmica, supõe a gestão das relações de amizades, com os professores, os posicionamentos diante dos assuntos estudantis e em alguns casos a administração das rotinas domésticas e financeiras. Em que medida estão posicionadas as questões de gênero quando se fala do ingresso, permanência, desistência ou formatura de mulheres em Engenharias e Cursos Tecnológicos como os que estamos trabalhando neste artigo? Narrativas provocadas sobre as vivências de universitárias da UTFPR-Guarapuava permitem dar voz a um conjunto diverso de ansiedades, de temores, de desafios e fatores que representam pressões na tomada de decisão sobre a própria formação.

\section{Os dilemas do novo: mulheres migrantes, cidade nova e universidade em construção}

Em relatos, observa-se que o ingresso no Curso Superior de Tecnologia em Manutenção Industrial (TMI) foi "uma experiência bem difícil no começo, com a maioria dos acadêmicos sendo homens e eu a única mulher. No primeiro mês pensei várias vezes em desistir” (R1). TMI é o curso de maior predominância masculina na UTFPR-Guarapuava. A proposta do curso atrai poucas estudantes (implantado desde 2014, de 23 mulheres que ingressaram, 18 desistiram e nenhuma se formou até o momento). Dificuldades de adaptação em função de hábitos que são diferentes para uma migrante em Guarapuava/PR, ou o "julgamento" de colegas homens em sala de aula enquanto tentava constituir um "círculo" próprio de amizades, também aparecem em outros relatos. "Ser nova" justificava comportamento arredio no espaço acadêmico (R2). O trato da adaptação ao espaço universitário tem sido elemento importante para a leitura da permanência de estudantes na universidade, haja vista que questões ligadas às condições de fazer amizade, apoio familiar, estrutura universitária capaz de orientar e apoiar estudantes no processo de transição da escola para o ensino superior são cruciais para o desenvolvimento (TEIXEIRA et al., 2008). Isso porque ocorre uma mudança brusca na vida dos/as estudantes na passagem para a universidade os/as deixam vulneráveis: “A minha família é do interior de Rebouças/PR. Não conhecia nada da cidade [de Guarapuava] e chegar aqui e ter esse choque de realidade foi uma coisa muito pesada" (R3). À dificuldade de adaptação à cidade, somou-se, logo no primeiro semestre de curso, a desistência de algumas colegas: "Aí uma das meninas voltou para o Pará e a outra desistiu. Fiquei sozinha. Do primeiro para o segundo período, durante as férias, acabei ficando sozinha, sem ninguém para conversar. Silêncio, de uma hora para outra" (R3). O primeiro semestre havia sido marcado, nesse sentido, por perdas simbólicas como o rompimento com a vida em comunidade do interior, mudança de residência e de cidade 
e, com isso, quebra da rotina diária com a família. Somava-se a isso a desistência de suas duas companheiras de moradia. Todos esses fatores contribuíram para que pensasse em desistir do curso já no primeiro momento.

O conjunto desses rompimentos e novas construções de subjetividade foram investigados pela historiadora Ana Martins (1992), considerando as décadas de 1950 e 1960 em Curitiba/PR. Martins (1992) observou experiências cotidianas de acadêmicas a partir da construção de vínculos de amizade, cumplicidade e solidariedade em meio à construção da vida profissional feminina em período singular marcado também por uma expansão de projetos de futuro e perspectivas de crescimento econômico nacionais na metade do século XX.

Em certa medida, parte dos elementos considerados por Martins ecoam, permanecem nas percepções relatadas (R3), já que a moradia com estranhos nos fala sobre experiências conflituosas, sobre amizade, solidão, tristeza ou alegria. Em meio a esses dilemas, há o caso de estudante que aproximou-se de um colega de curso, vindo a morar com ele, sanando, talvez, parte de suas angústias. $\mathrm{O}$ namoro e a vida a dois serviram de alento e ela afirma ter-se realizado com a filha do namorado, "um sol na minha vida", de acordo com seu relato. A experiência de vida heteronormativa e sua concretização parecem ter acomodado as ansiedades dela, um elemento determinante para sua permanência no curso. A situação de moradia vinculada ao processo de adaptação na universidade, considerando pressões familiares em torno da vida de uma mulher longe de casa também é observada quando de exigências familiares para que algumas estudantes vivam em pensionato feminino (R4).

Moradia, novas relações sociais também foram seguidas do dilema do espaço de construção da própria instituição, inicialmente sediada em campus de uma universidade já existente em Guarapuava, pública e estadual, com outros códigos, outras normas, outras dinâmicas.

Medos, inseguranças, instabilidades, como já dissemos, foram sentidas pelas estudantes em relação as primeiras impressões delas à Universidade, o primeiro dia de aula, pode ser contado pela via da violência simbólica, entendida como formas de segregação, preconceito, diferença ou indiferença sem necessariamente embate físico. Uma estudante, migrante e negra, vivendo em Guarapuava, lembra da exclusão operada por estudantes homens que chamavamna de "estranha" (R4). o que remete a estereótipos relacionados a seu corpo e raça. Esse binômio mulher/negra construíram as condições de desistência a partir da marcação de sujeitos afastados da produção do conhecimento, da ciência e, por consequência da universidade. A narrativa mostra a permanência da existência do estado de exclusão, especialmente constituído a partir de um duplo enfrentamento de questões raciais e de gênero. 
A construção dos primeiros momentos nesse espaço trouxeram estudantes de Engenharia para perto de cursos de Humanas (devido à configuração temporária do campus), e a relação com o espaço de uma instituição alheia pode ter influenciado, inclusive, a perspectiva de adaptação, pertencimento ou vivência acadêmica, conforme estudante e sua lembrança positiva acerca de uma "universidade mais habitável” (R3), diferente do campus próprio que veio a ser constituído; o tempo do campus novo já trazia outras experiências: o da opressão dos meninos da engenharia.

A leitura do espaço institucional sob a ótica da estudante, é um espaço que se distancia da comunidade, que promove a competitividade, parecendo estar separada da realidade do entorno do campus. Para outra estudante, contudo, pontua outras relações sentidas: a impessoalidade no campus UTFPR Pato Branco, de onde veio transferida, e a pessoalidade e a "humanidade" do campus de chegada, quando ainda era na Unicentro (R5). Também atribui o sentimento de 'família' ao campus temporário (R5).

$\mathrm{Na}$ medida em que o campus e seus cursos foram sendo construídos, o deslocamento geográfico da UTFPR-Guarapuava da estrutura provisória da Unicentro para o novo terreno, mais distante do centro da cidade, trouxe alguns entraves e novos desafios e dilemas para as mulheres ali matriculadas. Diversas entrevistadas relataram que, na universidade, deveriam se esforçar "como os homens". "Fazer igual os homens fazem", pressupõe muito esforço, e a mulher tem que dar o seu melhor para conseguir acompanhar, e chegar ao nível deles" (R2). Nessa reflexão com os estudantes, evidencia que eles são superiores em relação ao desenvolvimento no curso. Na sequência, adiciona um elemento no relato: eles são melhores porque tiveram experiências na área profissional, anteriores ao ingresso na universidade, e não porque naturalmente são mais habilidosos (R2).

Alguns elementos dessa narrativa são suficientes para explicar a concepção essencialista sobre as relações de gênero, percebida nas afirmativas desta estudante: "a mulher pensa de um jeito diferente do homem", ela "consegue pensar em cinco coisas diferentes ao mesmo tempo", “e mulher não, mulher conversa" e "dá uma humanizada no lugar" (R2).

Estudante4 (2018) cursou Engenharia Civil e observa que grande parte dos homens, inclusive docentes, adotavam práticas discriminatórias contra mulheres, expondo-as por meio de anedotas, "brincadeiras persistentes", de caráter desqualificador. Isso também foi sentido pelas entrevistadas, algo que já vem sendo pontuado por Tania Incerti (2017), ao discutir gênero e educação profissional no Instituto Federal do Paraná, campus Curitiba. A autora observa que as questões de gênero estão imbricadas em todo o processo educativo, naturalizadas e não 
questionadas, restando a falsa impressão de não existir desigualdades de gênero nesse espaço (INCERTI, 2017, p. 6).

O conteúdo das anedotas e "brincadeiras" preconceituosas tem como base o reforço de uma percepção de superioridade de uma pessoa sobre a outra, de uma condição social sobre outra, de uma percepção sobre nacionalidade, etnia, religião ou gênero, sempre relacionado a outras situações e/ou a outros sujeitos. Ou seja, é nas relações sociais que se criam as concepções que dão argumento para promover as piadinhas, o rir do outro, neste caso, é uma tentativa de colocá-lo numa condição de inferioridade, ou deixá-lo menor. E quando a piada ou a brincadeira têm conotação de gênero, como foi a situação apontada pela estudante, o fundamento está na compreensão machista nas relações sociais, em que se estabelece um juízo de valor vinculado às percepções de supostas diferenças entre os sexos, seguida da proposição de uma dada masculinidade. Ressalta-se que a questão do constrangimento pode ser agravada quando uma anedota é verbalizada por docentes que, em sala de aula, ocupam uma posição hierárquica superior que intimida aquelas que presenciam ou são alvo de tais situações.

Uma estudante contribui para a compreensão de como sutilmente estas relações acontecem no ambiente da universidade. Segundo a estudante, "Sempre tinha aquela: você não aguenta segurar isso! Era uma pecinha deste tamanhinho, você não aguenta segurar isso, deixa que eu pego para você, isso era uma coisa que me irritava tanto". O que aparentemente é uma forma de gentileza, para a estudante no processo relacional provocava irritação. Isso porque ao se colocar nessa condição, o colega parece estar subjugando a capacidade da colega, colocandoa em condição de inferior, menor, incapaz. Por outro lado, evidencia um traço de uma compreensão das relações de gênero na perspectiva da complementariedade, em que o homem considerado mais forte terá condições de ajudar a mulher que, nesse caso, não é capaz. Nas duas formas de perceber estas relações há um ranço das concepções machistas estabelecidas socialmente, que se discrimina as mulheres, com base em pressupostos estabelecidos a um estereótipo de feminilidade.

As relações de gênero em sala de aula aparecem, para a estudante, como o primeiro enfrentamento para conquistar um lugar na Engenharia. As situações vivenciadas são reflexo da construção social e histórica da profissão, vinculada ao masculino. Para a estudante, as brincadeiras e comportamentos machistas, são resultado do processo de formação escolar. Em suas palavras: "da aquela coisa estrutural de ensino médio de dividir meninos e meninas e tudo aquilo, reforçava isso. Então eles não esperavam tantas meninas num curso de Engenharia" (R5). A lembrança da estudante permite pensar o lugar da escola na construção da identidade de gênero e na forma como estabelecemos as relações sociais, pois como instituição, ela age 
diretamente nos corpos, a partir de regras de disciplinas e exigências comportamentais vinculadas ao que se espera de meninos e meninas (LOURO, 2016).

As relações de gênero construídas nos cursos de Engenharias e Tecnologias na UTFPR em Guarapuava permitem refletir sobre dificuldades sentidas pelas mulheres nesse espaço institucional, ainda permeado por atitudes preconceituosas, machistas, sexistas, misóginas e racistas, resultantes do processo histórico cultural do qual sujeitos que compõem essas relações são construídos. Concomitantemente, promove a reflexão de processos de micro rupturas (GUATTARI; ROLNIK, 2005), fissuras nas percepções do entendimento estereotipado de feminino e masculino, que podem contribuir para o surgimento de novas formas de subjetividades, novas configurações de existir nesse contexto.

Permanecer em cursos que exigem conhecimento matemático, que exigem bom desempenho em disciplinas das Exatas parece ser, nesse sentido, um dos elementos complicadores de distinção de gênero na UTFPR-Guarapuava. A repulsa e o medo das disciplinas de Exatas parecem estar vinculadas ao processo de escolarização e de socialização de meninas e meninos, como tem pontuado Casagrande e Carvalho (2011), que observaram a permanência de estereótipos criados sobre as habilidades de meninos e meninas nos ambientes escolares de ensino fundamental. O medo da matemática é construído no processo de formação escolar, nas relações cotidianas e familiares, e na falta de oportunidades em acessar recursos que as despertem para este conhecimento.

Entre permanecer e desistir na graduação em cursos nas áreas de exatas, existe a discussão sobre as dificuldades relacionadas às disciplinas matemáticas. Nesse sentido, é possível observar que as reprovações em uma ou mais disciplinas dessas áreas representam $40 \%$ de estudantes regulares no campus. Os dados relacionados ao índice de reprovação, atingem uma proporção maior ao refletirmos que cada estudante desse universo reprovou, no mínimo, em duas disciplinas, sendo comum a persistência de reprovação de três a 11 vezes numa mesma disciplina, especialmente nos cursos de engenharias. Quanto à reprovação entre homens e mulheres nas engenharias, verificamos uma diferença para menos no percentual de reprovação em disciplinas relacionadas às mulheres. Na Engenharia Civil, a diferença é de menos 15\% e na Engenharia Mecânica, 24\% a menos. Ou seja, no período analisado, constata-se que as mulheres nas Engenharias no campus da UTFPR-Guarapuava tiveram menos reprovações do que homens.

Nas tecnologias, os dados revelaram duas situações: em Tecnologia de Sistemas de Internet, $61 \%$ das estudantes estão retidas em seus cursos por reprovações em duas ou mais disciplinas, e na relação com os seus colegas, a diferença é de 9\%. No curso de TMI, não 
encontramos casos de reprovações entre as mulheres, curso em que elas representam 5\% das matrículas. Considerando as disciplinas que mais reprovam, por curso e por gênero, observa-se que: na Engenharia Civil, 43\% do total de estudantes regulares estão reprovados em duas ou mais disciplinas (as disciplinas que mais reprovam são Cálculo Diferencial e Integral 1, 41\%; Cálculo Diferencial e Integral 3, 19\%; Geometria Analítica e Álgebra Linear, 16\%, seguidas por Física 2, 14\%, e Física 1, 11\%). Em Engenharia Mecânica, o percentual de reprovação total é de 47\%. As disciplinas com maiores índices de reprovações são Cálculo Diferencial e Integral 1, 40\%; Geometria Analítica e Álgebra Linear, 29\%; Cálculo Diferencial e Integral 3, 20\%; Cálculo Diferencial e Integral 2, 13\%, e Cálculo Diferencial e Integral 4, 12\%. Mulheres reprovam mais em Geometria Analítica e Álgebra Linear.

Em TSI, 54\% de estudantes que estão em situação de reprovação. As disciplinas que mais reprovam são Introdução à Orientação a Objetos, 37\%; Pensamento Computacional e Fundamentos de Programação, 30\%; Desenvolvimento Para Web 2, 29\%; Estrutura De Dados 1, 27\%, e Linguagem Orientada a Objetos, 22\%. No curso de Tecnologia e Manutenção Industrial, as reprovações representam $43 \%$ do total matrículas. As disciplinas com maior índice de reprovações são Fundamentos Matemáticos, 50\%; Física, 41,07\%; Resistência dos Materiais, 14,25\%; Eletrônica, 17,85\%, e Eletricidade, 17,85\%.

Os dados demonstram que no período analisado (2019/2), as duas primeiras disciplinas com maior percentual de reprovação nos cursos ofertados pela UTFPR em Guarapuava fazem parte da grade curricular do primeiro, segundo e terceiro períodos, que correspondem aos três primeiros semestres da inserção acadêmica.

As diferenças na reprovação por gênero, relacionadas às disciplinas nos cursos de Engenharias e Tecnologias estão também vinculadas a ideias de competitividade, individualismo e emulação presentes na educação superior. "Ninguém ajuda ninguém”, ou o popular "Se vire" são expressões marcantes desse processo, tanto reproduzidas por docentes como pelo corpo discente. Como observam Casagrande e Carvalho (2011, p. 303), “o rendimento escolar está permeado pelas relações de gênero quer quando se analisam os números propriamente ditos, quer quando se analisam as justificativas para explicar a diferença no rendimento de alunas e alunos".

Não se sentir suficiente, tentar e não conseguir, estudar muito e ser avaliada com conceitos ou notas baixas, gera sentimentos de incapacidade, causa frustração e são causas de desistência entre os cursos da UTFPR. Uma estudante lembra de como passou pela experiência de frustração, sentindo-se "um lixo" (R5). A narrativa exprime o sentimento de incapacidade na relação vivida no espaço acadêmico e essa afirmação remete à argumentação de Arlette 
Farge (2015), ao pontuar que nas palavras de sofrimento há sistemas relacionais e culturais que possibilitam a compreensão de um universo refletido em pertencimentos, fracassos, derrotas.

As narrativas das estudantes mostram pelo menos duas formas de compreensão das relações de gênero: uma percepção essencialista, no aspecto de naturalização de habilidades femininas e masculinas, e uma perspectiva construtivista, ressaltando elementos de que essa percepção de feminino e masculino são constructos sociais, na vinculação com o corpo e a cultura (BUTLER, 2016).

A concepção essencialista sobre as relações de gênero e mulher, tem como base as diferenças biológicas entre os sexos, entre homens e mulheres como justificativa para a desigualdade social, os adeptos a esta leitura, argumentam sobre "uma suposta natureza humana, inscrita nos corpos, na forma de um instinto ou energia sexual, que conduziria o comportamento de homens e mulheres" (SABOYA, 2013, p. 2).

A trajetória acadêmica das mulheres entrevistadas desemboca no processo de desistir da graduação. Assim, a forma das escolhas, a adaptação ao espaço institucional, as relações pessoais e de gênero, as disciplinas e as reprovações, mesclados com as assimilações e com os sentidos atribuídos por elas, compõem a subjetividade do trajeto. Desistir da universidade foi um processo elaborado por sujeitos.

Sofrimento, culpa e/ou alívio circundam a decisão. Para Farge (2015, p. 17), "a dor revela a formidável tensão que faz com que se confrontem a ordem e sua negação, a violência e o sentimento vitimário, o ódio e o desejo". As narrativas sobre as motivações para interromper o percurso da graduação aparecem como queixas do estado de renúncia e também de dor. As dificuldades são assimiladas por uma estudante como fracasso pessoal, individualizado. Sua mãe não concordava com a desistência e insistia com a estudante para que continuasse o curso (R6). Não se identificando com o curso, não se sentindo bem no ambiente, abandonou a instituição, mas o que permaneceu no registro acadêmico foi a mensagem "Desistência gerada pelo sistema, falta de matrícula” (R6). Ademais, ao analisar os motivadores de desistência, também destaca uma percepção dicotômica entre as Ciências Exatas e Humanas, supondo que o seu perfil pessoal é mais compatível com as Humanidades. A estudante permaneceu na graduação por cinco semestres, e sua trajetória acadêmica foi marcada pelo envolvimento em ações junto ao movimento estudantil e na participação de projetos desenvolvidos no campus. $\mathrm{O}$ fato de gostar de falar e interagir, aparece para a ela como incompatível com o ambiente da UTFPR. Como motivo de desistência, no sistema de registros acadêmicos consta "Desistência gerada no sistema, falta de matrícula”. 
Outra discente também foi uma discente que relacionou desistência com o ambiente universitário. Entrou na UTFPR e foi uma das fundadoras do Diretório Central de Estudantes (DCE), incluindo uma agenda de lutas contra o machismo, que foi "extremamente combatida pelos estudantes e alguns docentes das Engenharias" (R5). Ao denunciar machismo institucional e pelo fato de ter participado na fundação do DCE, sentiu-se desgastada, afirmando ter desistido por não ter conseguido alcançar as notas mínimas de aprovação, em ambiente complicado e hierarquizado: "havia docentes que diziam 'Eu sou doutor e eu sei. Você não sabe nada'.

Outra entrevistada lembra que os motivos de desistência do curso de Engenharia Civil na UTFPR foram distância da família e transtornos psicológicos, depois de ter permanecido por cinco semestres na universidade. Experiência similar é a de outra estudante que também passou por doença de origem emocional, que pode ter sido potencializada nas relações estabelecidas no ambiente universitário. Diagnosticada com depressão severa, abandonou o curso pelo fato de ficar cada vez mais difícil e em razão do lugar do campus (R7). E continua: "Depois que eu saí da UTF, eu fiquei seis meses sem sair de casa" (R7). A estudante lembra que sofreu muitas perdas durante o período que esteve na UTFPR. Segundo ela, "sempre fui muita ativa, eu fazia judô, participava de campeonato, sempre tive uma vida muito agitada; depois que eu entrei na faculdade, fui perdendo tudo" (R7). O desamparo ou a falta de acolhia por colegas e pela instituição geraram a desistência.

Já outra estudante, negra, dizia que "eu não consigo nem passar em frente a UTFPR". Segundo ela, situações vivenciadas no campus a levaram a um estado de renúncia, de afastamento, de um espaço físico institucional, configurando uma desistência compulsória, que tem marcas como sofrimento, adoecimento e abdicação da formação profissional. A condição econômica familiar da estudante, que também pesou sobre a decisão de desistência se apresenta numa cartografia considerada por Guattari e Rolnik (2005) como perversa, construída por séculos de exclusão e segmentação social.

\section{Considerações finais}

Os dados arrolados a partir da relação entre relatos provocados na pesquisa e documentos de outra natureza permitem observa que estudantes, especialmente mulheres, desistem em grande número já no primeiro semestre de um curso superior de Engenharia ou de Tecnologias. Em todos os cursos o campus da UTFPR em Guarapuava, o percentual de desistência nesse período é acima de 40\%. É importante que se diga, que os semestres de 
permanência dos estudantes não correspondem ao período que o estudante estava no momento da desistência. O percentual de reprovação é alto e isso gera retenção dos/as estudantes em seus cursos.

No curso de TMI, das 17 estudantes desistentes, 10 desistiram no primeiro semestre e dos 178 homens, 121 deixaram o curso nessa fase. Em relação aos números, observamos que o tempo máximo de permanência é de seis semestres para as mulheres, enquanto que $32 \%$ dos homens permaneceram de 3 a 10 semestres antes de desistir.

Em TSI, assim como em TMI, o percentual de desistência no primeiro período esteve acima e 50\% para homens e para mulheres, no entanto, observamos um tempo maior de permanência dos/as estudantes até desistirem, sendo que $46 \%$ das mulheres e $43 \%$ dos homens, permaneceram na graduação de dois a quatorze semestres. Ressaltamos que apenas um estudante permaneceu neste curso por quatorze semestres.

Entre os/as desistentes no primeiro semestre em Engenharia Mecânica, o percentual de mulheres é de $54 \%$, enquanto que entre os homens é de $44 \%$. A porcentagem de estudantes que permanecem em até de meses oito meses é $9 \%$ dos/as desistentes, sendo um número maior de estudantes que prolongam a permanência no curso.

Em Engenharia Civil o percentual de desistência, no primeiro semestre é de $47 \%$ para homens e $40 \%$ para mulheres, sendo que os/as demais estudantes permanecem até quatorze meses no caso dos homens e dez meses entre as mulheres. Notamos que doze estudantes ficaram até oito semestres para então desistir.

Saltam aos olhos os números elevamos de estudantes que desistem antes de completar o primeiro semestre. São eles que dão peso para compor o alto percentual de desistentes. Em números absolutos, considerando homens e mulheres, no curso de TMI dos 175 desistentes, 94 não encerraram o primeiro semestre, para TSI dos 337, 193 desistiram no primeiro semestre. Nas Engenharias a situação é semelhante, para a Civil dos 197, 79 desistiram antes de finalizar o semestre e na Mecânica entre os/as 308 desistentes, 71 saíram sem concluir o curso.

Os dados levantados a partir das entrevistas realizadas sinalizam para a necessidade de ações relacionadas às discussões de gênero no ambiente universitário, haja vista que essas estruturas institucionais não estão abertas para a acolhida das vivências pessoais da sua comunidade. Evidenciam que a intersecção raça-gênero ou outras que também envolvem classe, marcam a subjetividade das mulheres e contribuem para a compreensão da trajetória vivida, dos sentimentos experimentados e singularizam o processo.

No espaço universitário, há a necessidade de reprojetar ações educacionais que possam ampliar, incluir e favorecer a permanência de todos e todas. Os dados apresentados permitem 
visualizar algumas situações vividas pelas estudantes que deixaram o espaço institucional. São questões pertinentes, que podem contribuir para a ampliação de estudos no campo, para a construção e consolidação de novas práticas institucionais no ensino superior, mas especialmente para a reflexão em torno das condições e da promoção de formação superior nas áreas de Engenharia e Tecnologias que possam incorporar o desafio da equidade de gênero ou do combate oficial à discriminação racial ou de classe como fundamentos políticos da própria formação.

\section{Referências}

ANDRADE, A. M. J. de. Desempenho acadêmico, permanência e desenvolvimento psicossocial de universitários: relação com indicadores de assistência estudantil. 2014. Dissertação (Mestrado em Psicologia) - Programa de Pós-Graduação em Psicologia, Universidade Federal do Rio Grande do Sul, Porto Alegre, 2014.

BITENCOURT, S. M. As relações de gênero na engenharia. Diálogos num campo de saber/poder masculino. In: FERREIRA, M. de S. (org.). Desigualdades de gênero no Brasil: novas ideias e práticas antigas. Belo Horizonte: Argvmentvm, 2010.

BOURDIEU, P. Os usos sociais da ciência: por uma sociologia clínica do campo científico. São Paulo: Unesp, 2004.

BOURDIEU, P.; PASSERON, J. C. Escritos de educação. Petrópolis: Vozes, 1998.

BRASIL. Lei Federal 9.394, de 20 de dezembro de 1996. Estabelece as diretrizes e bases da Educação Nacional. DOU, Brasília, 23 dez. 1996. Disponível em: www.planalto.gov.br/ccivil_03/LEIS/L9394.htm. Acesso em: 15 out. 2019.

BRASIL. Lei Federal 11.184 de 07 de outubro de 2005. Dispõe sobre a transformação do Centro Federal de Educação Tecnológica do Paraná em Universidade Tecnológica Federal do Paraná e dá outras providências. DOU, Brasília, 10 out. 2005. Disponível em: www.planalto.gov.br/ccivil_03/_Ato2004-2006/2005/Lei/L11184.htm. Acesso em: 15 out. 2019.

BRASIL. Decreto Federal 6.096, de 24 de abril de 2007. Institui o Programa de Apoio a Planos de Reestruturação e Expansão das Universidades Federais - REUNI. Brasília, 2007. Disponível em: www.planalto.gov.br/ccivil_03/_Ato2007-2010/2007/Decreto/D6096.htm. Acesso em: 15 out. 2019.

BUTLER, J. Corpos que pesam: sobre os limites discursivos do "sexo". In: LOURO, G. L. (org.). O corpo educado: pedagogias da sexualidade. Belo Horizonte: Autêntica, 2016. p. 151-198.

CASAGRANDE, L. S. Entrevista com Lindamir Salete Casagrande, por Lucas Bueno de Freitas. Cad. gên. Tecnol., Curitiba, v. 11, n. 37, p. 73-80, jan./jun. 2018. 
CASAGRANDE, L. S.; CARVALHO; M. G. de, (orgs.). Igualdade na diversidade: enfrentando o sexismo e a homofobia. Curitiba: UTFPR, 2011.

CHASSOT, A. A ciência é masculina? São Leopoldo: Unisinos, 2003.

COLLINS, P. H. Black feminist throught: knowledge, consciousness, and the politics of empowerment. 2. ed. New York: Routledge, 2000.

CRENSHAW, K. W. et al. (orgs.). Seeing Race Again: countering colorblindness across the disciplines. Oakland: University of California Press, 2019.

DUBAR, C. Trajetórias sociais e formas identitárias: alguns esclarecimentos conceituais e metodológicos. Educação e Sociedade, Campinas, v. 19, n. 62, p. 13-30, abr. 1998.

FARGE, A. Lugares para a história. Belo Horizonte: Autêntica, 2015.

GISI, M. L.; PEGORINI, D. G. As políticas de acesso e permanência na educação superior: a busca da igualdade de resultados. Revista on line de Política e Gestão Educacional, Araraquara, v. 20, n. 1, p. 21-37, 2016. Disponível em:

https://periodicos.fclar.unesp.br/rpge/article/view/9390. Acesso em: 15 out. 2019.

GUATTARI, F.; RONILK, S. Micropolítica: cartografias do desejo. 7. ed. Petrópolis: Vozes, 2005.

INCERTI, T. G. V. Brincadeiras persistentes, desigualdades de gênero presentes: relações de gênero na educação profissional, uma análise a partir da percepção de estudantes do IFPR. 2017. Dissertação (Mestrado em Tecnologia e Sociedade) - Universidade Tecnológica Federal do Paraná, Curitiba, 2017.

KLANOVICZ, L. R. F. História, gênero e ciência: mulheres engenheiras no sul do Brasil. Revista Venezolana de Estudios de La Mujer, Caracas, v. 16, n. 37, p. 105-112, 2011.

LOMBARDI, M. R. Perseverança e resistência: a Engenharia como profissão feminina. 2004. Tese (Doutorado em Educação) - Programa de Pós-Graduação em Educação. Universidade Estadual de Campinas, Campinas, 2004.

LOURO, G. P. O corpo educado: pedagogias da sexualidade. 3. ed. Belo Horizonte: Autêntica, 2016.

MARTINS, A. P. V. Um lar em terra estranha: a aventura da individualização feminina a casa da estudante universitária de Curitiba nas décadas de 50 e 60. 1992. Dissertação (Mestrado em História do Brasil) - Programa de Pós-Graduação em História. Universidade Federal do Paraná, Curitiba, 1992.

PORTELLI, A. O que faz a história oral diferente. Projeto história. São Paulo, v. 4, p. 25-39, 1997.

SABOYA, M. C. L. Relações de gênero, ciência e tecnologia: uma revisão da bibliografia nacional e internacional. Educação, Gestão e Sociedade: Revista da Faculdade Eça de Queiróz, São Paulo, v. 3, n. 12, p. 1-26, 2013. 
SARDENBERG, C. B. Da crítica feminista à ciência a uma ciência feminista? Labrys: Estudos Feministas. Brasília/Montréal/Paris, 2007. v. 11.

SCHIEBINGER, L. O feminismo mudou a ciência? Bauru: Edusc, 2001.

SVARCZ, K. C. Relações de gênero na Física: a inserção de mulheres na "Ciência Hard" da UFSC (1980-2010). 2017. Dissertação (Mestrado em História) - Programa de Pós-Graduação em História do Tempo Presente, Universidade do Estado de Santa Catarina, Florianópolis, 2017.

SOBREIRA, J. de L. Estudantes de Engenharia na UTFPR: uma abordagem de gênero. 2006. Dissertação (Mestrado em Tecnologia e Sociedade) - Programa de Pós-Graduação em Tecnologia e Sociedade, Universidade Tecnológica Federal do Paraná, Curitiba, 2006.

TABAK, F. O laboratório de Pandora: estudos sobre a ciência no feminino. Rio de Janeiro: Garamond, 2002.

TEIXEIRA, M. A. P. et al. Adaptação à universidade em jovens calouros. Psicologia Escolar e Educacional, São Paulo, v. 12, n. 1, p. 185-202, 2008. 